\title{
Prevalence and severity of anemia among pregnant women in primary health centers/Erbil City
}

\author{
Rushna Ghazi Abdulwahid \\ Surgical Specialty Hospital/Cardiac Center \\ Erbil DOH \\ Erbil Iraq \\ rushnamahamad@yahoo.com
}

\author{
Hamdia Mirkhan Ahmed \\ Head of Midwifery Department \\ College of Nursing \\ Hawler Medical University \\ hamdia.mirkhan@nur.hmu.edu.krd
}

\begin{abstract}
Anemia in pregnancy is a major public health problem, especially in developing countries. Nutritional anemia is the most common type of anemia worldwide and mainly includes iron, folic acid, vitamin $B 12$ and vitamin $C$ deficiencies. Iron deficiency contributes to half of the burden of anemia globally. The objectives of this study were to find out the prevalence and severity of anemia among pregnant women. A descriptive study was conducted on 600 pregnant women, during the period October 2015 to November 2016 at four primary health care centers in Erbil city. Data gathered through interview with study sample and filling questionnaire format and reviewing their antenatal records. Blood hemoglobin level was measured to assess the severity of anemia. Chi-square test and regression were used to analyze the data. Prevalence of anemia was $46.2 \%$, and $67.1 \%$ of the anemic women had mild anemia. There was a significant association of severity of anemia with wife education and occupation, smoking, the number of abortions and cesarean section, ante partum hemorrhage, taking tablets of iron and folic acid per month. The study concluded that prevalence of anemia considered high in Erbil city, the highest percentage had mild anemia.
\end{abstract}

Keywords: Prevalence, anemia, pregnancy

\section{INTRODUCTION}

Anemia in pregnancy is a major public health problem, especially in developing countries. It affects $41.8 \%$ of pregnant women globally [1]. Anemia in pregnancy is defined by the World Health Organization (WHO) as a hemoglobin concentration below $11 \mathrm{~g} / \mathrm{dL}$ [2,3]. According to WHO definition, the prevalence of anemia in pregnancy varies between $15 \%$ and $67 \%$ worldwide, with one of the highest (30-65\%) in sub-Saharan countries, and the lowest (15- 25\%) in developed countries. This rates seem too high even in high resource countries where under nutrition is almost absent [4].

Anemia during pregnancy is considered severe when hemoglobin concentration is less than $7.0 \mathrm{~g} / \mathrm{dL}$, moderate when hemoglobin falls between 7.0-9.9 g/dL and mild from 10.0-11 g/dL [5].

The cause of anemia in pregnancy is multi-factorial. Iron, folate, vitamin $\mathrm{B}_{12}$ and vitamin $\mathrm{A}$ deficiencies as well as intestinal parasitic infections, malaria, chronic illness have all been shown to be the main causes of anemia among pregnant women [1]. Nutritional anemia is the most common type of anemia worldwide and mainly includes iron, folic acid, vitamin $\mathrm{B}_{12}$ and vitamin
$\mathrm{C}$ deficiencies. Iron deficiency contributes for half of the burden of anemia globally. Iron deficiency affects 1.3 to 2.2 billion persons out of those $50 \%$ are women of reproductive age. In Ethiopia nearly $17 \%$ of women with age $15-49$ are anemic of these $22 \%$ are pregnant women [6].

Anemia in pregnant women has severe consequences on health, social, and economic development. Anemic pregnant women will be at risk of low physical activity, increased maternal morbidity and mortality, especially those with severe anemia. In addition, both pregnant women and their neonates encounter negative consequence including fetal anemia, low birth weight (LBW), preterm delivery, intrauterine growth restriction and perinatal mortality [1]. Anemia in pregnancy is associated with adverse consequences both for the mother and the fetus. Studies have shown that the adverse consequences of maternal anemia may affect not only the neonate and infant but also increase the risk of non-communicable diseases when the child grows into an adult and the risk of low birth weight in the next generation [7]. Low maternal hemoglobin levels are associated with increased risk of preterm delivery, low birth weight babies, APGAR score $<5$ at $1 \mathrm{~min}$ and intrauterine fetal demise [8].

The study aimed to find out the prevalence and severity of anemia among pregnant women and its relationship with some demographic and obstetric variables.

\section{METHODS AND MATERIALS}

A cross- sectional study was conducted among pregnant women who attended antenatal care in primary health care centers (PHCCs) / Erbil city, during the period October/ 1 st 2015 to November/ 13 / 2016. Four primary health care centers from totally 19 , were randomly selected according to geographic area Brayati from north, Kurdistan from south, Malafande from east, and Mahamad bajalan from west. A purposive sampling of 600 pregnant women was included in the study. Sample size was estimated using the general formula for targeted population size, allowed error $5 \%$, prevalence (ratio of the studied phenomenon in the population in similar study) and using the $95 \%$ confidence interval. The sample size of each primary health care center was according to their ratio in the targeted population. Mothers who had the following criteria were included: pregnant woman who were in $1^{\text {st, }} 2^{\text {nd }}, 3^{\text {rd }}$ trimester of pregnancy and those who accept to participate in the study. Woman's with history of chronic hypertension, diabetes, thyroid, cardiac diseases and systematic lupus 
erythematosis, hemoglobinopathies such as thalassemia and those who hah early \& late vaginal bleeding or ante partum hemorrhage (abruptio placenta and placenta previa) and hemorrhoid were excluded. Prior to data collection the official permission was obtained from College of Nursing, Erbil General Directorate of Health, and primary health care centers for carrying out the study in Erbil City. Face to face interview method and reviewing antenatal card was used for data collection and filling a designed questionnaire after taking permission \& explanation the objectives of the study to the mother's. Blood hemoglobin level was measured to assess severity of anemia. Severity of anemia is determined according to Alene \& Dohe as the following: Mild (hemoglobin level between 10.0- $11 \mathrm{gm} / \mathrm{dl}$ ), Moderate (hemoglobin level between 7.0- $9.9 \mathrm{gm} / \mathrm{dl}$ ), Sever (hemoglobin level less than $7 \mathrm{gm} / \mathrm{dl}$ )[5].

Approval of the Ethical Committee from the College of Nursing, in addition to approval of General directorate of primary health care center was secured, mothers consent verbally was taking to participate in the study. Data were entered into a computer using the Statistical Package for Science Services (SPSS version 23). Frequency, percentage and chi-square test was used for interpretation of data.

\section{RESULTS}

The highest percentage $57.3 \%$ of the study sample aged between 25-36 years old, while the lowest percentage $8 \%$ aged between $37-48$ years old. Regarding residency, all participants of the study sample were living in urban area.

In the present study the prevalence of anemia during pregnancy was $46.2 \%$, regarding severity of anemia the highest percentage $67.1 \%$ of the study sample had mild anemia, while the lowest percentage $32.9 \%$ of the study sample had moderate anemia, and there was no cases for severe anemia (Table1).

The results also indicated that there was a highly statistically significant association between severity of anemia with wife education \& smoking ( $p<0.001)$, and significant association with husband education and wife occupation, while there was no significant association with other variables (Table 2). A significant association between severities of anemia with number of SC was found in the present study, while there was no significant association between severity of anemia with other variables (Table 3). Table 4 shows that there was a significant association between severity of anemia with number of taking tabs/month of iron \& folic acid, while there was no significant association between other obstetrical characteristics during current pregnancy.

Logistic regression analysis revealed that, lower professional job, taking $<30$ tabs of iron $\&$ folic acid per month, public clinic attending for antenatal care were indicated as risks for anemia. On the other hand, high professional job and birth spacing $<2$ years were indicated no risks for anemia ( $p>0.05 \mathrm{OR}=3.062$, $1.433,1.039$, respectively)(Table 5).

Table 1- Prevalence and severity of anemia among study sample

\begin{tabular}{|l|c|c|}
\hline Prevalence & F & \% \\
\hline Anemic & 277 & 46.2 \\
\hline Non-anemic & 323 & 53.8 \\
\hline Total & $\mathbf{6 0 0}$ & $\mathbf{1 0 0}$ \\
\hline Severity of anemia & & \\
\hline Moderate & 91 & 32.9 \\
\hline Mild & 186 & 67.1 \\
\hline Total & $\mathbf{2 7 7}$ & $\mathbf{1 0 0}$ \\
\hline
\end{tabular}

\section{DISCUSSION}

WHO global database on anemia estimated the classification of anemia as a significance problem of public health if the prevalence of anemia be $\geq 40.0$ [9]. The result of the present study shows the prevalence of anemia among pregnant women $46.2 \%$. So according WHO classification it indicates as severe public problem. This results are similar to the results of other studies done in Bali, Indonesia in 2002 which was $46.2 \%$, in northern Tanzania was $47.4 \%$ in 2011, and $48.2 \%$ in South-East Asia and $44.2 \%$ in Eastern Mediterranean by WHO 2005, in South Eastern Nigeria in 2007 was $40.4 \%$, in Kakamega County, Kenya was $40 \%$ in $2014[3]$.

Prevalence of anemia during pregancy in the present study was higher than the results of other studies done in Wolayita Sodo Town, Southern Ethiopia in 2015 was $39.94 \%$, in Makkah, Saudi Arabia was 39\% in 2012, in Southeast Ethiopia was $27.9 \%$ in 2014 , in Europe was $25.1 \%$ and in Americas $24.1 \%$ by WHO , in Nablus, Palestine was $21.7 \%$ in 2007, in Mekelle town was $19.7 \%$ in 2014, in the lower North Of Thailand was $17.5 \%$ in 2012, in Kerman, Iran was $4.7 \%$ in 2010. While the prevalence of anemia in the present study was lower than the results of other studies done in Korangi Industrial Area was 54.3\% in 2010, inBaghdad was $55.4 \%$ in 2012, in an urban area of Eastern Ethiopia was $56.8 \%$ in 2014 , in Africa was $57.1 \%$ by WHO , in eastern Sudan was $62.6 \%$ in 2005, in ruralpopulation of Kolar district of India was $64 \%$ in 2015, in a MalariaEndemic Area in Benin was $68.3 \%$ in 2012, in an urban area of Pakistan was $90.5 \%$ in 2008 [3].

Regarding severity of anemia $67.1 \%$ had mild anemia and $32.9 \%$ had moderate anemia and there was no detecting for severe anemia in the present study. Kefiyalew et at, found that $55 \%, 32.5 \%, 12.5$ of study sample had mild, moderate and severe anemia respectively, which was consistent to the results of the present study [10]. Dim \& Onah reported $90.7 \%$ had mild anemia, $9.3 \%$ had moderate anemia and no cases of severe anemia was detected on their studies which was consistent to the results of the present study [2]. Gedefaw et al, found in their study that $30.34 \%$ of the 
study sample had mild anemia, 60\% had moderate anemia and $9.66 \%$ had severe anemia which was in contrast to results of the present study [1]. Naz \& Begum found these rates regarding severity of anemia in their study: $23.18 \%$ mild anemia, $37.7 \%$ moderate anemia, $27.27 \%$ severe anemia and $11.8 \%$ very severe anemia which were in contrast to the results of the present study [11].

Table 2- Association of severity of anemia with socio-demographic characteristics $(N=277)$

\begin{tabular}{|c|c|c|c|c|c|}
\hline \multirow[t]{2}{*}{ Variables } & \multicolumn{2}{|c|}{ Moderate } & \multicolumn{2}{|c|}{ Mild } & \multirow{2}{*}{$\begin{array}{c}\text { P-value } \\
\text { Chi-square test }\end{array}$} \\
\hline & $\mathbf{F}$ & $\%$ & $\mathbf{F}$ & $\%$ & \\
\hline $\begin{array}{l}\text { Age group/years } \\
13-24 \\
25-36 \\
37-48\end{array}$ & $\begin{array}{l}35 \\
46 \\
10\end{array}$ & $\begin{array}{l}36.5 \\
29.3 \\
41.7\end{array}$ & $\begin{array}{c}61 \\
111 \\
14\end{array}$ & $\begin{array}{l}63.5 \\
70.7 \\
58.3\end{array}$ & 0.315 \\
\hline $\begin{array}{l}\text { Wife Education } \\
\text { Illiterate } \\
\text { Read and write only } \\
\text { Primary school } \\
\text { Intermediate school } \\
\text { Secondary school } \\
\text { Institute, college, and above }\end{array}$ & $\begin{array}{c}20 \\
0 \\
8 \\
15 \\
18 \\
30 \\
\end{array}$ & $\begin{array}{c}54.1 \\
0.0 \\
16.7 \\
39.5 \\
46.2 \\
30.3 \\
\end{array}$ & $\begin{array}{l}17 \\
16 \\
40 \\
23 \\
21 \\
69 \\
\end{array}$ & $\begin{array}{c}45.9 \\
100.0 \\
83.3 \\
60.5 \\
53.8 \\
69.7 \\
\end{array}$ & $<0.001$ \\
\hline $\begin{array}{l}\text { Husband Education } \\
\text { Illiterate } \\
\text { Read and write only } \\
\text { Primary school } \\
\text { Intermediate school } \\
\text { Secondary school } \\
\text { Institute, college, and above }\end{array}$ & $\begin{array}{c}12 \\
2 \\
10 \\
15 \\
12 \\
40\end{array}$ & $\begin{array}{l}46.2 \\
66.7 \\
17.2 \\
26.3 \\
33.3 \\
41.2\end{array}$ & $\begin{array}{c}14 \\
1 \\
48 \\
42 \\
24 \\
57\end{array}$ & $\begin{array}{l}53.8 \\
33.3 \\
82.8 \\
73.7 \\
66.7 \\
58.8\end{array}$ & 0.014 \\
\hline $\begin{array}{l}\text { Wife Occupation } \\
\text { High professional job } \\
\text { Lower professional job } \\
\text { Unskilled workers } \\
\end{array}$ & $\begin{array}{c}0 \\
12 \\
79 \\
\end{array}$ & $\begin{array}{r}0.0 \\
26.1 \\
35.7 \\
\end{array}$ & $\begin{array}{c}10 \\
34 \\
142 \\
\end{array}$ & $\begin{array}{c}100.0 \\
73.9 \\
64.3 \\
\end{array}$ & 0.035 \\
\hline $\begin{array}{l}\text { Husband Occupation } \\
\text { High professional job } \\
\text { Lower professional job } \\
\text { Unskilled workers }\end{array}$ & $\begin{array}{c}2 \\
38 \\
51\end{array}$ & $\begin{array}{l}14.3 \\
31.1 \\
36.2\end{array}$ & $\begin{array}{l}12 \\
84 \\
90\end{array}$ & $\begin{array}{l}85.7 \\
68.9 \\
63.8\end{array}$ & 0.217 \\
\hline $\begin{array}{l}\text { Economic status level } \\
\text { Low economic status }<90 \\
\text { Middle economic status 90-120 } \\
\text { High economic status } 121-150\end{array}$ & $\begin{array}{l}42 \\
29 \\
20\end{array}$ & $\begin{array}{l}30.9 \\
36.7 \\
32.3\end{array}$ & $\begin{array}{l}94 \\
50 \\
42\end{array}$ & $\begin{array}{l}69.1 \\
63.3 \\
67.7\end{array}$ & 0.676 \\
\hline $\begin{array}{l}\text { Smoking } \\
\text { Passive } \\
\text { None }\end{array}$ & $\begin{array}{l}19 \\
72\end{array}$ & $\begin{array}{l}20.2 \\
39.3\end{array}$ & $\begin{array}{c}75 \\
111\end{array}$ & $\begin{array}{l}79.8 \\
60.7\end{array}$ & 0.001 \\
\hline
\end{tabular}

Table 3- Association of severity of anemia with obstetrical history of the study sample $(n=277)$

\begin{tabular}{|c|c|c|c|c|c|}
\hline \multirow[t]{2}{*}{ Variables } & \multicolumn{2}{|c|}{ Moderate } & \multicolumn{2}{|c|}{ Mild } & \multirow{2}{*}{$\begin{array}{c}\text { P-value } \\
\text { Chi-square tes }\end{array}$} \\
\hline & $\mathbf{F}$ & $\%$ & $\mathbf{F}$ & $\%$ & \\
\hline $\begin{array}{l}\text { Gravidity } \\
\text { Primigravida } \\
\text { Multigravida } \\
\end{array}$ & $\begin{array}{c}37 \\
54 \\
\end{array}$ & $\begin{array}{c}36.3 \\
30.9\end{array}$ & $\begin{array}{l}65 \\
121 \\
\end{array}$ & $\begin{array}{r}63.7 \\
69.1 \\
\end{array}$ & 0.559 \\
\hline $\begin{array}{l}\text { Parity } \\
\text { Nulliparous } \\
\text { Primiparous } \\
\text { Multiparous } \\
\text { Grand multipara }\end{array}$ & $\begin{array}{c}44 \\
21 \\
13 \\
13\end{array}$ & $\begin{array}{l}31.9 \\
34.4 \\
29.5 \\
38.2\end{array}$ & $\begin{array}{c}94 \\
40 \\
31 \\
21\end{array}$ & $\begin{array}{l}68.1 \\
65.6 \\
70.5 \\
61.8\end{array}$ & 0.890 \\
\hline $\begin{array}{l}\text { Number of CS } \\
\text { None } \\
1-3 \\
4-6 \\
\end{array}$ & $\begin{array}{c}70 \\
19 \\
2\end{array}$ & $\begin{array}{c}30.3 \\
43.2 \\
100\end{array}$ & $\begin{array}{c}161 \\
25 \\
0\end{array}$ & $\begin{array}{c}69.7 \\
56.9 \\
0\end{array}$ & 0.032 \\
\hline $\begin{array}{l}\text { Birth spacing / Years } \mathbf{n = 1 8 5} \\
<2 \\
=>2\end{array}$ & $\begin{array}{l}30 \\
37 \\
\end{array}$ & $\begin{array}{c}30.9 \\
42.0 \\
\end{array}$ & $\begin{array}{l}67 \\
51\end{array}$ & $\begin{array}{l}69.1 \\
58.0\end{array}$ & 0.066 \\
\hline
\end{tabular}


Table 4- Association of severity of anemia with current obstetrical characteristics of the study sample (N=277)

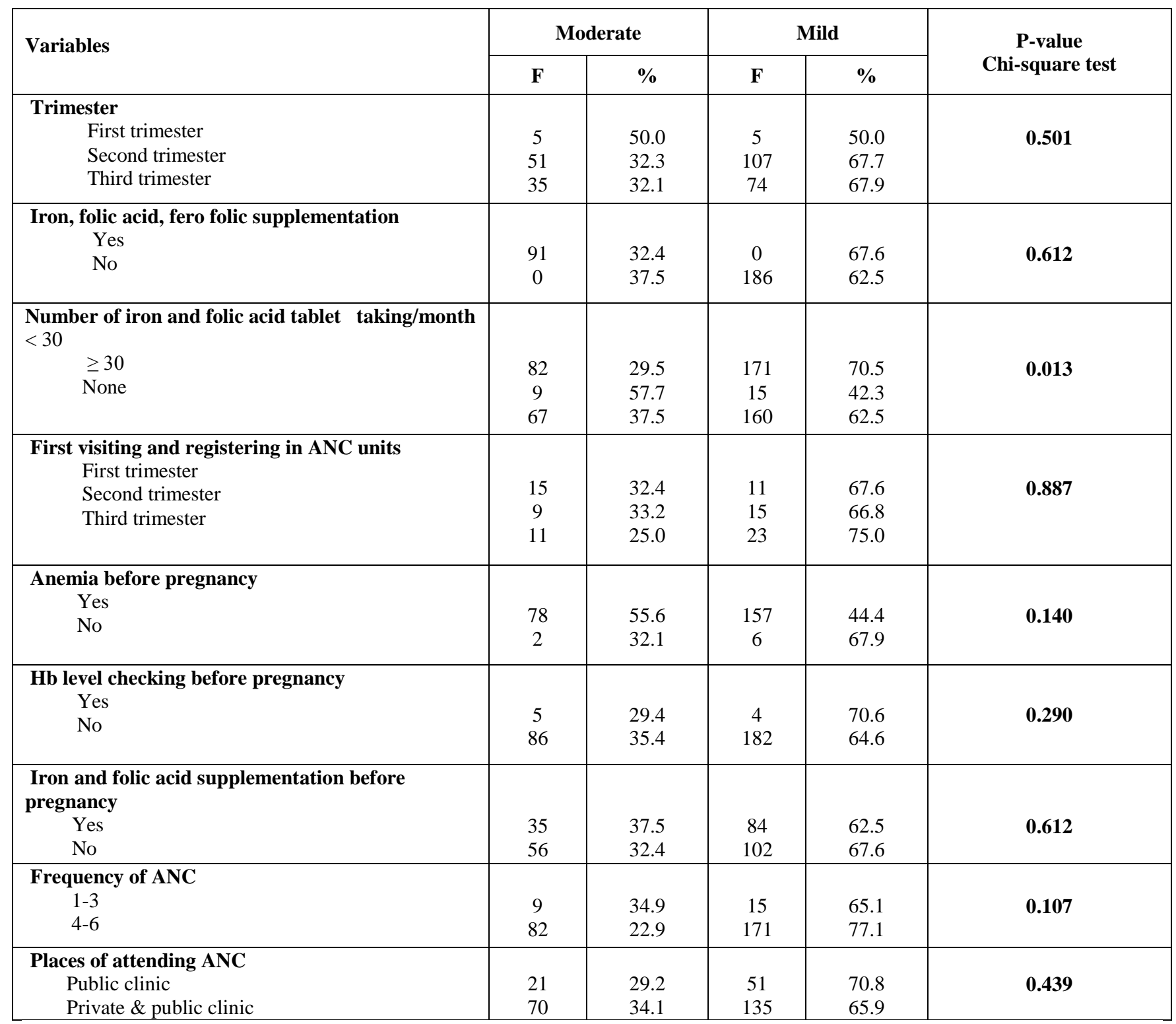

Table 5- Logistic regression analysis of the factors associated with anemia

\begin{tabular}{|c|c|c|c|}
\hline Variables & P- value & Odd's Ratio & $95 \%$ CI of OR \\
\hline $\begin{array}{l}\text { Wife Occupation } \\
\text { High professional job } \\
\text { Lower professional job } \\
\text { Unskilled workers (reference category) }\end{array}$ & $\begin{array}{l}0.270 \\
0.041\end{array}$ & $\begin{array}{l}3.062 \\
0.543\end{array}$ & $\begin{array}{c}0.419-22.377 \\
0.302-0.976\end{array}$ \\
\hline $\begin{array}{l}\text { Birth spacing / Years } \\
\quad<2 \\
\quad \geq 2 \text { (reference category) }\end{array}$ & 0.118 & 1.433 & $0.913-2.249$ \\
\hline $\begin{array}{l}\text { Number of iron and folic acid tablet takin } \\
\quad<30 \\
\geq 30 \text { (reference category) }\end{array}$ & $<0.001$ & 0.147 & $0.054-0.400$ \\
\hline $\begin{array}{l}\text { Places of attending ANC } \\
\text { Public clinic } \\
\text { Private \& public clinic (reference category) }\end{array}$ & 0.037 & 0.611 & $0.385-0.970$ \\
\hline
\end{tabular}


The results of the present study showed that there was a highly significant association of severity of anemia with wife education and smoking, these results agreed with results of Mirzaie et al, who found that there was a highly significant association of prevalence of anemia with maternal education and smoking [12]. Aikawa et al, mentioned that there was a highly significant association of $\mathrm{Hb}$ levels with maternal education which was consistent to the results of present study [13]. Khapre et $a l$, results agreed with results of the present study regarding education which indicated that there was a significant relation of severity of anemia with maternal education [14].

There was no significant association of age group with severity of anemia in the present study, which was consistent to the results of Siteti et al, \& Mirzaie et al, who found that there was no significant association of severity of anemia with maternal age [12,15].

A study done by Morsy \& Alhady, who conducted descriptive study among 400 pregnant women to determine the prevalence of anemia and the influence of some factors associated with anemia during pregnancy in Egypt, they mentioned that maternal age has strongly associated with anemia level, which is disagreed with the results of present study [16].

Rajamouli et al, conducted a cross-sectional study on pregnant women, attending the maternity clinic of rural health training centre and teaching hospital of Chalmeda Anand Rao institute of medical sciences Karimnagar Telangana, India,to study the prevalence of anemia in rural pregnant women and the factors associated with anemia, they found that there was a significant association of severity of anemia with wife occupation which was consistent to the results of present study [17]. Studies of Khapre et al, also agreed with the present study regarding wife occupation who found that there was a significant association of severity of anemia with maternal occupation [14].

Soh et al, conducted a cross-sectional study in urban areas in Malaysia to determinethe $\mathrm{Hb}$ levels of antenatal mothers and their association with various socioeconomic characteristics, they found that there was a high significant association between $\mathrm{Hb}$ level with economic status, which was in contrast to the results of present study, while it was agreed with that in which wife occupation have significant association with $\mathrm{Hb}$ levels and maternal occupation [18].

The present study show that there was no significant association of severity of anemia with iron, folic acid, fero folic supplementation in current pregnancy, which was in contrast to results of a study done by Mirzaie et $a l$, and Aikawa et al, who mentioned that there was a significant association of $\mathrm{Hb}$ levels with iron supplementation [12,13]. While results of Lelissa et al, agreed with the results of present study regarding iron \& folic acid supplementation, who mentioned that there was no significant association of severity of anemia with iron and folic acid supplementation [19].
Viveki et al, and Lelissa et al, mentioned on their results that there was no significant association of severity of anemia with trimester of pregnancy, which was consistent to the results of present study [20].

Regarding birth spacing $<2$ years in the present study there was no indicated for risks of anemia, which was in contrast to results of Abdelhafez and El-Soadaa who mentioned that women with short inter pregnancy periods were at more risk of developing anemia during pregnancy [21], while it was consistent to results of Abu-Hasira who found that decreased birth spacing didn't show such association [22].

Bekele et al, conducted a cross-sectional study to assess the prevalence and factors associated with anemia among pregnant women attending antenatal care in health institutions of Arba Minch town, Gamo Gofa zone, Southern Ethiopia, who mentioned that birth spacing was independent predictors of anemia in pregnancy, which was consistent to the results of present study [23].

\section{CONCLUSION}

The prevalence of anemia during pregnancy considered high in Erbil city, the majority had mild anemia. Wife occupation, number of iron tablet taking per month and place of attending for antenatal care were risk factors for anemia during pregnancy.

\section{REFERENCE}

[1] Gedefaw L., Ayele A., Asres Y. and Mossie A. (2015).Anemia and Associated Factors among Pregnant Women Attending Antenatal Care Clinic in Wolayita Sodo Town, Southern Ethiopia. Ethiop J Health Sci. 2015 Apr; 25(2): 155-162. Available from:

http://www.ncbi.nlm.nih.gov/pmc/articles/PMC447 $\underline{8267 /}$.

[2] C. Dim, and H. Onah, "The Prevalence of Anemia Among Pregnant Women at Booking in Enugu, South Eastern Nigeria," MedGenMed. 9(3): 11. PMCID: PMC2100084, 2007.

[3] World Health Organization (WHO), "Nutrition of women in the preconception period during pregnancy and the breastfeeding period," Provisional agenda item 13.3, A65/12. 16 March 2012.

[4] E. Nkwabong, and J. Kasia, "Should We Revisit The Current Definition Of Anemia In Pregnancy," Journal of Pregnancy and Child Health. Available from:http://dx.doi.org/10.4172/2376127X.1000e111, 2015.

[5] K. Alene, and A. Dohe, "Prevalence of Anemia and Associated Factors among Pregnant Women in an Urban Area of Eastern Ethiopia," Article ID 561567, 7pages. Available from: http://dx.doi.orjrfjeliulwiuuidn. 25 August 2014.

[6] M. Yesuf, and M. Wassie, "Prevalence and associated factors of anemia among pregnant 
women of Mekelle town: a cross sectional study," BMC Research Notes 7:888, 2014.

[7] K. Kalaivani, "Prevalence \& consequences of anemia in pregnancy," Indian J Med Res 130, pp 627-633, November 2009.

[8] F. Lone, R. Qureshi and F. Emanuel, "Maternal anaemia and its impact on perinatal outcome," Tropical Medicine and International Health, volume 9 no 4 pp 486-490, April 2004.

[9] B. Benoist, E. Mclean, I. Egli, and M. Cogswell, "Worldwide prevalence of anemia," WHO global database on anemia, 1993-2005.

[10] F. Kefiyalew, E. Zewene, Y. Asres and L. Gedefaw, "Anemia among pregnant women inSoutheast Ethiopia: prevalence, severity and associated risk Factors," BMC Research Notes 7:771 [Available from: http://www.biomedcentral.com/1756-0500/7/771], 2014.

[11] H. Naz, and B. Begum, "Prevalence and associated risk factors of anemia in pregnant women in a teaching hospital, Korangi industrial area," Pak J Surg, 29(2):131-133, 2013.

[12] F. Mirzaie, N. Eftekhari, S. Goldozeian, and J. Mahdavini, "Prevalence of anemia risk factors in pregnant women in Kerman," Iran Iranian Journal of Reproductive Medicine, Vol.8. No.2. pp: 66-69, Spring, 2010.

[13] R. Aikawa, N. Khan, S. Sasaki, and C. Binns, "Risk factors for iron-deficiency anemia among pregnant women living in rural Vietnam," Public Health Nutrition: 9(4), 443-448, 18 July 2005.

[14] M. Khapre, R. Meshram and A. Mudey, "Study on multiple causal factors associated with varying degree of anemia among rural pregnant women," International Journal of Medical Science and Public Health | Vol 2 | 266-270, 2013.

[15] M. Siteti1, S. Namasaka, O. Ariya, S. Injete and W. Wanyonyi, "Anaemia in pregnancy: Prevalence and possible risk factors in Kakamega County, Kenya," Science Journal of Public Health, Published available from: (http://www.sciencepublishinggroup.com/j/sjph), 23. May 20, 2014.

[16] N. Morsy and S. Alhady, "Nutritional Status and Socio-Economic Conditions Influencing Prevalence Of Anaemia In Pregnant Women,"
International journal of scientific \& technology research volume 3, issue 7, july, 2014.

[17] J. Rajamouli, A. Ravinder, S. Reddy and S. Pambi, "Study on Prevalence of Anemia among Pregnant Women attending Antenatal Clinic at Rural Health Training Centre (RHTC) and Chalmeda Anand Rao Institute of Medical Sciences Teaching Hospital, Karimnagar, Telangana, India," International Journal of Contemporary Medical Research. Volume 3 | Issue 8 | August 2016.

[18] K. Soh., E. Tohit, S. Japar, S. Geok, N. Rahman and R. Raman, "Anemia among Antenatal Mother in Urban Malaysia," Journal of Biosciences and Medicines, 3, 6-11. Available from: http://www.scirp.org/journal/jbm 2015.

[19] D. Lelissa, M. Yilma, M. Shewalem, A. Abraha, M. Worku, H. Ambachew and M. Birhaneselassie, "Prevalence of Anemia Among Women Receiving Antenatal Care at Boditii Health Center, Southern Ethiopia," Clinical Medicine Research, Volume 4, Issue 3, 79-86, .May 2015.

[20] R. Viveki, A. Halappanavar, P. Viveki, S. Halkis, V. Maled and P. Deshpande, "Prevalence of Anaemia and Its Epidemiological Determinants in Pregnant Women," Al Ameen J Med S c I, 5 (3):2 $16-223,2012$.

[21] M. Abdelhafez and S. El-Soadaa, "Prevalence and Risk Factors of Anemia among a Sample of Pregnant Females Attending Primary Health Care Centers in Makkah," Saudi Arabia.Pakistan Journal of Nutrition, 11 (12): 1113-1120, 2012.

[22] A. Abu-Hasira, Iron Deficiency Anemia among Pregnant Women in Nablus District; Prevalence, Knowledge, Attitude and Practices. A thesis Submitted in Partial Fulfillment of the Requirements for the Degree of Master of Public Health Science, Faculty of Graduate Studies, at AnNajah National University, Nablus, Palestine 2007.

[23] A. Bekele, M. Tilahun and A. Mekuria, "Prevalence of Anemia and Its Associated Factors among Pregnant Women Attending Antenatal Care in Health Institutions of Arba Minch Town, Gamo Gofa Zone, Ethiopia: A Cross-Sectional Study," Volume Article ID 1073192, 9 pages, Available from: $\quad$ http://dx.doi.org/10.1155/2016/1073192, 